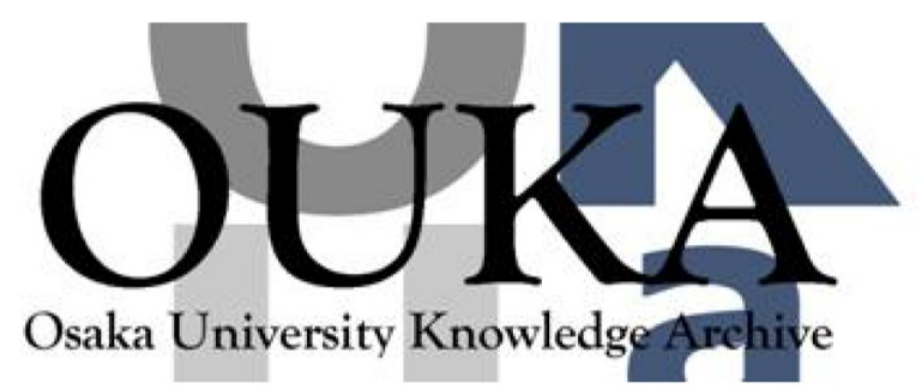

\begin{tabular}{|c|l|}
\hline Title & $\begin{array}{l}\text { Hugoniot measurements for polyimide with laser } \\
\text { and explosives }\end{array}$ \\
\hline Author(s) & Ozaki, N.; Tanaka, K. A. ; Sasatani, Y. et al. \\
\hline Citation & Physics of Plasmas. 10(6) p. 2475-p. 2479 \\
\hline Issue Date & $2003-06$ \\
\hline oaire:version VoR \\
\hline URL & https://hdl. handle. net/11094/3069 \\
\hline rights & \\
\hline Note & \\
\hline
\end{tabular}

Osaka University Knowledge Archive : OUKA

https://ir. Library. osaka-u. ac. jp/

Osaka University 


\title{
Hugoniot measurements for polyimide with laser and explosives
}

\author{
N. Ozaki, ${ }^{a)}$ K. A. Tanaka, Y. Sasatani, K. Fujita, K. Takamatsu, and M. Nakano \\ Institute of Laser Engineering, Osaka University, Suita, Osaka 565-0871, Japan \\ and Faculty of Engineering, Osaka University, Suita, Osaka 565-0871, Japan \\ M. Yoshida, K. Okada, E. Takahashi, and Y. Owadano \\ National Institute of Advanced Industrial Science and Technology, Tsukuba, Ibaraki 305-8565, Japan \\ H. Takenaka \\ NTT Advanced Technology Co., Shinjuku, Tokyo 163-0431, Japan \\ K. Kondo \\ Materials and Structures Laboratory, Tokyo Institute of Technology, Yokohama, \\ Kanagawa 226-8503, Japan
}

(Received 14 January 2003; accepted 12 March 2003)

\begin{abstract}
Equation-of-state measurements for a polyimide are presented. High-power $\mathrm{KrF}$ laser and chemical explosive-driven experiments provided Hugoniot data on the polyimide up to about $65 \mathrm{GPa}$. Conventional reflected-light measurements in the explosive experiments and velocity interferometry measurements in the laser experiments were performed. From both laser and explosive results the change of Hugoniot was indicated at near $30 \mathrm{GPa}$. (c) 2003 American Institute of Physics.
\end{abstract}

[DOI: $10.1063 / 1.1572490]$

\section{INTRODUCTION}

The experimental and theoretical investigations of equation-of-state (EOS) for materials at high pressure and density are of fundamental interest to astrophysics, ${ }^{1}$ geophysics, ${ }^{2}$ inertial fusion energy (IFE) research, ${ }^{3,4}$ and other related fields. In particular IFE studies, the compression efficiency and shock structure in fusion capsules critically depend on the EOS. ${ }^{3}$ Such hydrodynamic and thermodynamic characteristics are usually estimated by simulation codes employing EOS models ${ }^{5}$ or tables. ${ }^{6}$

Plastics play important roles as the IFE shell materials of the capsule and have been used extensively in the fundamental experiments, such as Rayleigh-Taylor instability ${ }^{7}$ and fast ignition research. ${ }^{8}$ Plastics meet the immediate requirements for an IFE pellet shell: low density, smooth outer and inner surfaces, sphericity, and concentricity. Future IFE experiments, especially those conducted at cryogenic temperatures, would be more feasible if the targets possessed additional properties: high tensile strength, large elastic module, great room-temperature permeability, large radiation resistance, high thermal conductivity, low electrical conductivity, and large opacity at a laser wavelength at $351 \mathrm{~nm}$. Polyimide (PI) is a polymeric material with a potential meeting these additional requirements. PI shells were first suggested for an ignition target of the National Ignition Facility (NIF). ${ }^{4,9}$ Recently, high quality millimeter-sized PI shells have been fabricated using vapor deposition polymerization ${ }^{10}$ and removing nonvolatile solvent. ${ }^{11}$ One of the recently developed $\mathrm{PI}^{12}$ applications (fluorinated polyimide, $\mathrm{C}_{33} \mathrm{H}_{12} \mathrm{~N}_{2} \mathrm{O}_{4} \mathrm{~F}_{12}$ ) is an ablator of the multilayered flyer, which was demonstrated to generate high pressures without the preheat problem. ${ }^{13-15}$ As

${ }^{a)}$ Electronic mail: nozaki@ile.osaka-u.ac.jp there are no Hugoniot data for the PI, the shock compressed state should be studied in order to design targets using the PI.

Generally EOS experiments measure two independent variables under shock compression simultaneously, and calculate the remaining variables from the Rankine-Hugoniot relations

$$
\begin{aligned}
& P-P_{0}=\rho_{0} U_{S} u_{p}, \\
& \rho / \rho_{0}=U_{S} /\left(U_{S}-u_{p}\right),
\end{aligned}
$$

and

$$
E-E_{0}=\frac{1}{2}\left(P+P_{0}\right)\left(1 / \rho_{0}-1 / \rho\right),
$$

where $P, \rho$, and $E$ are the pressure, density, and internal energy behind the shock, $U_{S}$ and $u_{p}$ are the shock and particle velocity, the 0 subscripts denote the initial condition. ${ }^{16}$

Impedance matching (IM) is the most popular technique to determine the Hugoniot EOS point, and measures the two shock velocities simultaneously in two materials: an EOS standard and an unknown sample. ${ }^{17}$ This method makes it possible to decide one EOS point of the sample based on the EOS of the standard reference. By using the IM method, conventional shock-drive techniques, such as gas-guns or explosives, usually achieve a measurement accuracy of $1 \%$ equal or less.

Powerful lasers have extended the capability of EOS studies, providing extreme high pressures not accessible by the conventional techniques. ${ }^{18}$ Laser experiments have provided relatively accurate data with a few percent of error, particularly in IM experiments based on the shock velocity measurements. ${ }^{19}$

In this paper, Hugoniot data of a polyimide are reported. Experiments based on the IM method with a high-power $\mathrm{KrF}$ laser are described in detail. The laser-driven data are com- 


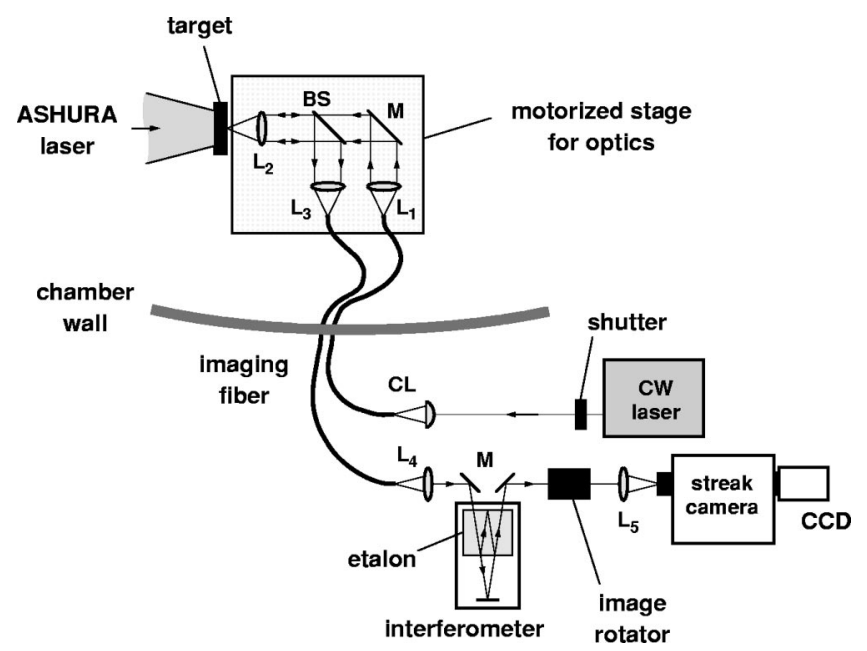

FIG. 1. Line-ORVIS experimental setup. A continuous-wave probe laser is line focused by a cylindrical lens; CL and passed through an imaging fiber into a vacuum chamber. A mechanical shutter is arranged which has a maximum shutter speed of $1 / 25$ second. Lenses, beam splitter, and mirrors are denoted as $L_{1}, \mathrm{BS}$, and $\mathrm{M}$, respectively. The light is transferred to the outside of the chamber by another imaging fiber. The image can be rotated by dove prism to horizontally adjust according to the streak slit.

pared to reliable explosive-driven results. The relationship between Hugoniot variables $\left(U_{S}\right.$ and $\left.u_{p}\right)$ and the change of Hugoniot above $30 \mathrm{GPa}$ is obtained.

\section{EXPERIMENTS}

\section{A. KrF laser drive}

Laser experiments were performed with the ASHURA/ Super-ASHURA laser facility ${ }^{20}$ at the Electrotechnical Laboratory (ETL). ${ }^{21}$ The facility is a high power KrF laser system. The wavelength and the maximum energy are $249 \mathrm{~nm}$ and $660 \mathrm{~J}$, respectively. The pulse duration was approximately $10 \mathrm{~ns}$ of a full-width at half-maximum (FWHM) with a near-Gaussian pulse shape. In this experiment, one beam was used at around $100 \mathrm{~J}$ energy and the normal incidence to the target surface, which was coupled with a phase zone plate (PZP) to eliminate large-scale spatial intensity modulations and obtain a flat-top intensity profile in focal spot. The focal spot diameter was approximately $500 \mu \mathrm{m}$ at FWHM. The corresponding laser-intensity is around 5.1 $\times 10^{12} \mathrm{~W} / \mathrm{cm}^{2}$.

In the laser experiment, the line-imaging optically recording velocity interferometer system (Line-ORVIS) ${ }^{22}$ was used to measure the Hugoniot EOS of PI. The experimental configuration is shown in Fig. 1. The probe laser was a continuous wavelength $(\mathrm{CW})$ laser of up to $5 \mathrm{~W}$ power. The wavelength was $532 \mathrm{~nm}$. The probe laser was line-focused on the entrance side of an imaging fiber by a cylindrical lens with a focal length $f=15 \mathrm{~mm}$ and passed through the imaging fiber with a diameter of $1.2 \mathrm{~mm}$ and a length of $3 \mathrm{~m}$ into a vacuum chamber. In the chamber, the probe was image relayed to the target rear surface by two lenses; $L_{1}$ and $L_{2}$ with a different focal length $\left(f_{1}=12 \mathrm{~mm}\right.$ and $f_{2}=15 \mathrm{~mm}$, respectively) from the output side of the fiber. The width of the beam focused on the surface was approximately $400 \mu \mathrm{m}$. (a)

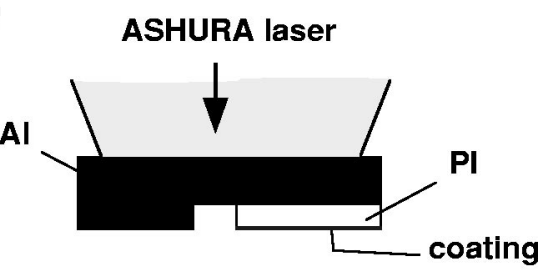

(b)

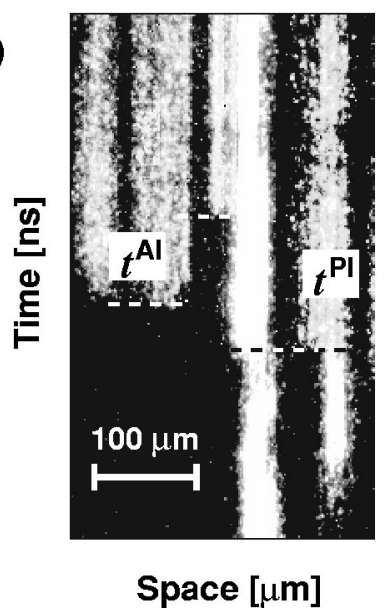

FIG. 2. (a) IM target schematic. Both steps are around $30 \mu \mathrm{m}$ thickness. (b) Typical streaked image. Time proceeds from the top to the bottom. The shock-transit times, $t^{\mathrm{Al}}$ and $t^{\mathrm{PI}}$ are approximately $4.7 \mathrm{~ns}$ and $7.5 \mathrm{~ns}$.

Reflected light from the target was collimated by $L_{2}$ and $L_{3}$ lens $\left(f_{3}=12 \mathrm{~mm}\right)$. One end of another imaging fiber with the same effective diameter was fixed on the image point of $L_{3}$. This optics system was mounted on a motorized stage for alignment in the vacuum chamber, as shown in Fig. 1. A target holder was mounted on another motorized stage (not shown in Fig. 1). The image was transferred to the outside of the chamber through the fiber. The light from the other end of the fiber was collected by a lens $L_{4}\left(f_{4}=25 \mathrm{~mm}\right)$. The light was passed through an etalon as the interferometer whose sensitivity, fringe constant was $3.164 \mathrm{~km} / \mathrm{s} /$ fringe. Finally, the light was collimated by a lens $L_{5}\left(f_{5}=100 \mathrm{~mm}\right)$ and was imaged as a set of bright fringe spots on the slit of a streak camera coupled with a charge-coupled-device (CCD) camera. The streaked image was recorded as a $512 \times 512$ pixel data with 16 bits by the CCD camera.

The Doppler shift of the reflected probe light is represented as a fringe shift at the output of the velocity interferometer. ${ }^{23}$ The fringe phase is proportional to the velocity of the moving material surface. Measuring free-surface velocity $U_{f}$, we can estimate a particle velocity in a shocked state from the free-surface velocity, for example, such as an assumption: $U_{f}=2 u_{p}$. If shock velocity is measured from the step structure of target, a Hugoniot point can be absolutely determined from the two independent Hugoniot valuables, the $U_{S}$ and $U_{f} / 2$. However, at high-pressure shocked states the reflected light from the surface is not often maintained because of scattering by the rapid change of the surface condition. Thus we designed experiments using doublestep target based on the IM method [Fig. 2(a)]; the ORVIS works as an instrument for both velocimetry and reflected measurements. 
Aluminum ( $\mathrm{Al}$ ) was used as a standard with well-known Hugoniot. We used one-dimensional Lagrangian hydrodynamic code ${ }^{14}$ to optimize the base and steps thicknesses in which steady shock propagated. Typical thickness of base was $150 \mu \mathrm{m}$ and those of $\mathrm{Al}$ and PI steps were $30 \mu \mathrm{m}$, respectively. The rear surface of PI was overcoated with a thin Al layer of $1000 \AA$ to reflect the probe light. Each step height was measured by a laser displacement gauge with a minimum scale value of $0.01 \mu \mathrm{m}$. The initial density of $\mathrm{Al}$, $\rho_{0}^{\mathrm{Al}}$, was $2.71 \mathrm{~g} / \mathrm{cm}^{3}$ and that of PI, $\rho_{0}^{\mathrm{PI}}$, was $1.50 \mathrm{~g} / \mathrm{cm}^{3}$ with errors of less than $1 \%$, respectively.

\section{B. Chemical explosive drive}

Explosive-driven experiments were carried out with several ten Mega-J class of chemical explosives at the National Institute of Materials and Chemical Research (NIMC) ${ }^{21}$ Explosive plane generators were used for planar shock-wave formation. These generators consist of nitromethane as lowvelocity explosives and the compound of hydrazine nitrate and hydrazine hydrate as high-velocity explosives. Generated pressure was changed by varying the sets of high explosives and the materials and thicknesses of the base and flyer plates. The base and flyer plates were Al alloy (7075 and $52 \mathrm{~S})$ and copper $(\mathrm{Cu})$. The plate surfaces were polished to sustain uniform shock waves. Mirrors were attached to the free surfaces of the base and the steps. An argon (Ar) or krypton $(\mathrm{Kr})$ flash light reflects off the mirrors on the plate surfaces. The reflected light was recorded by a streak camera. We can measure the arrival time of the shock front at the mirror surfaces from the change of reflectivity. This kind of conventional experiment is described in many references. ${ }^{17}$

\section{RESULTS AND DISCUSSIONS}

Figure 2(b) shows an example of the velocimeter result in the laser-driven experiments. Time proceeds from the top to the bottom. The Al step is on the left and the PI is on the right. We can find that the fringe pattern changes (PI side) or vanishes $(\mathrm{Al})$ at the shock emergencies. The time intervals, $t^{\mathrm{Al}}$ and $t^{\mathrm{PI}}$ correspond to the transit times of the shock through both steps. In this data, the $t^{\mathrm{Al}}$ and $t^{\mathrm{PI}}$ were $4.69 \mathrm{~ns}$ and $7.52 \mathrm{~ns}$, respectively. As the step heights were known, the shock velocity of Al, $U_{S}^{\mathrm{Al}}$, was $6.44 \mathrm{~km} / \mathrm{s}$ and that of PI, $U_{S}^{\mathrm{PI}}$, was $3.99 \mathrm{~km} / \mathrm{s}$.

Al Hugoniot had been accurately measured over a wide range of pressures. Here we used a linear relationship between $U_{S}^{\mathrm{Al}}$ and $u_{p}^{\mathrm{Al}}$ suggested by Mitchell et al., ${ }^{24}$

$$
U_{S}^{\mathrm{Al}}=(5.386 \pm 0.047)+(1.339 \pm 0.021) u_{p}^{\mathrm{Al}} .
$$

Thus the $u_{p}^{\mathrm{Al}}$ and the pressure $P^{\mathrm{Al}}$ were determined as 0.79 $\mathrm{km} / \mathrm{s}$ and $13.7 \mathrm{GPa}$, respectively. When the shock wave propagates through the interface between $\mathrm{Al}$ and $\mathrm{PI}$, an unloading wave is reflected in the shocked Al. The unloadingwave state is given by the intersection of the isentrope of $\mathrm{Al}$ and the Rayleigh line of PI; $P=\rho_{0}^{\mathrm{PI}} \cdot U_{S}^{\mathrm{PI}} \cdot u_{p}$ in $P-u_{p}$ plane. Here the isentrope was assumed to be the reflection of $\mathrm{Al}$ Hugoniot, because the pressure range was low enough. This assumption may lead to less than a few percent to the error of $u_{p}$. The calculated particle velocity and pressure in PI were
$1.15 \mathrm{~km} / \mathrm{s}$ and $6.9 \mathrm{GPa}$, respectively. The accuracy was $2 \%$ in $U_{S}^{\mathrm{PI}}, 3 \%$ in $u_{p}^{\mathrm{PI}}$, and $4 \%$ in $P^{\mathrm{PI}}$, respectively.

However, the highest-pressure data in the laser experiment had an error larger than $10 \%$. The errors in target thicknesses and diagnostics resolution mainly contribute to this. The Al step was glued on Al substrate with diluted adhesive. Since the PI also did not have thermal plasticity, the same fabrication technique was applied. The layer thicknesses were few percent of step thicknesses. Since the shock velocity was fast in the highest-pressure case, the temporal resolution in relation to the shock transit-time becomes worse. Other factors relevant to the target: initial densities and standard EOS errors are small enough (1\% or less). In our previous experiments the spatial uniformity of the shock was shown to be flat within a $300 \mu \mathrm{m}$ diameter and the temporal steadiness was approximately $10 \mathrm{~ns} .{ }^{15}$ Taking into account the low irradiation intensity and the thickness of the target base-plate, the preheating effect should be negligible. In the ORVIS results, the significant reduction of reflectivity or of fringe shift was not detected before shock arrivals at Al surface, confirming the negligible preheat. The detection limit of this velocimeter was better than $0.31 \mathrm{~km} / \mathrm{s}$. This velocity corresponds to an expansion velocity at a temperature of about $0.1 \mathrm{eV}$ in $\mathrm{Al}$.

Chemical explosive-driven results and the experimental conditions are listed in Table I. The data accuracy was better than a few percent. The errors also are shown in the Table. In the explosive experiments, the target metrology and surface roughness cause the errors. When the shock velocity of the standard is close to its bulk sound velocity, the error, moreover, becomes large. ${ }^{25}$

All experimental results are plotted in Fig. 3. Open circles and solid diamonds indicate explosive-driven and laser-driven data, respectively. Solid and dotted curves are drawn to show the change of PI Hugoniot in both Figs. 3(a) and 3(b). The curves in Fig. 3(a) correspond to those in Fig. 3(b). The change of PI Hugoniot can be clearly found in the $U_{S}-u_{p}$ plane [Fig. 3(b)]. The first curve is a linear-fit to the data below $30 \mathrm{GPa}$ pressure, and the second is above the pressure. The $c_{0}$ and $s$ in the first curve were estimated as 2.15 and 1.65 (root mean square). The slope changes at $u_{p}$ $=2.6 \mathrm{~km} / \mathrm{s}$. This could be due to a phase change. The phase change could originate mainly from the separation of covalent bonds between carbon and hydrogen atoms in PI. At several $10 \mathrm{GPa}$, the temperature of the compounds consisting mainly of carbon and hydrogen can be predicted to reach several thousand Kelvin. The final state of shock-compressed materials is significantly different from the initial state and at the same time simpler than the initial structures. Then it is reasonably expected that in this temperature range under a strong shocked state, the covalent bonds are insignificant because of thermal dissociation, and each component acts chemically inert. According to previous works, ${ }^{26}$ in this pressure region the hydrocarbon data are qualitatively consistent with an assumption that hydrogen is in a condensed molecular phase and carbon is in the diamond phase; it is energetically favorable to replace the $\mathrm{H}-\mathrm{C}$ bonds with two different covalent bonds, $\mathrm{H}-\mathrm{H}$ bonds to form molecular hydrogen and $\mathrm{C}-\mathrm{C}$ bonds to form a diamond-like structure. In several hy- 
TABLE I. Conditions and results from explosive experiments for PI. Dashes in flyer column denote direct explosive drive. Step thicknesses are measured with an accuracy of better than $\pm 3 \mu \mathrm{m}$. The ambiguity of shock transit time is calculated from the standard deviation of shock arrival time.

\begin{tabular}{|c|c|c|c|c|c|c|c|}
\hline $\begin{array}{l}\text { Shot } \\
\text { No. }\end{array}$ & Flyer & Target & $\begin{array}{l}\text { Thickness } \\
(\mu \mathrm{m})\end{array}$ & $\begin{array}{l}\text { Transit time } \\
\text { (ns) }\end{array}$ & $\begin{array}{l}\text { Shock velocity } \\
(\mathrm{km} / \mathrm{s})\end{array}$ & $\begin{array}{l}\text { Particle velocity } \\
\qquad(\mathrm{km} / \mathrm{s})\end{array}$ & $\begin{array}{l}\text { Pressure } \\
(\mathrm{GPa})\end{array}$ \\
\hline \multirow[t]{2}{*}{ 9812_03 } & - & Al 7075 & 1967.7 & $299.08 \pm 0.617$ & $6.579 \pm 0.017$ & $1.014 \pm 0.012$ & $18.71 \pm 0.234$ \\
\hline & & PI & 500.0 & $104.32 \pm 0.385$ & $4.793 \pm 0.034$ & $1.423 \pm 0.017$ & $10.23 \pm 0.144$ \\
\hline \multirow[t]{2}{*}{ 9812_05 } & $\mathrm{Al}$ & Al 52S & 1987.0 & $249.28 \pm 0.054$ & $7.971 \pm 0.012$ & $1.882 \pm 0.020$ & $39.57 \pm 0.441$ \\
\hline & & PI & 514.0 & $82.36 \pm 0.285$ & $6.241 \pm 0.046$ & $2.505 \pm 0.009$ & $23.44 \pm 0.193$ \\
\hline \multirow[t]{2}{*}{ 9812_06 } & - & PMMA & 1882.9 & $352.94 \pm 0.646$ & $5.335 \pm 0.013$ & $1.792 \pm 0.008$ & $11.34 \pm 0.060$ \\
\hline & & PI & 518.7 & $107.31 \pm 2.153$ & $4.834 \pm 0.101$ & $1.694 \pm 0.008$ & $12.28 \pm 0.263$ \\
\hline \multirow[t]{2}{*}{ 9812_07 } & - & $\mathrm{Cu}$ & 1972.8 & $372.33 \pm 2.665$ & $5.299 \pm 0.039$ & $0.920 \pm 0.007$ & $43.48 \pm 0.344$ \\
\hline & & PI & 504.8 & $110.77 \pm 0.302$ & $4.557 \pm 0.030$ & $1.563 \pm 0.035$ & $10.68 \pm 0.249$ \\
\hline \multirow[t]{2}{*}{ 9812_08 } & - & $\mathrm{Al} 52 \mathrm{~S}$ & 3479.6 & $464.87 \pm 0.074$ & $7.485 \pm 0.007$ & $1.549 \pm 0.019$ & $30.57 \pm 0.384$ \\
\hline & & PI & 466.7 & $83.46 \pm 0.110$ & $5.592 \pm 0.037$ & $2.099 \pm 0.004$ & $17.61 \pm 0.120$ \\
\hline \multirow[t]{2}{*}{ 9812_09 } & $\mathrm{Cu}$ & $\mathrm{Cu}$ & 1965.7 & $338.92 \pm 0.067$ & $5.800 \pm 0.009$ & $1.252 \pm 0.008$ & $64.78 \pm 0.419$ \\
\hline & & PI & 494.9 & $91.08 \pm 1.063$ & $5.434 \pm 0.071$ & $2.084 \pm 0.010$ & $16.99 \pm 0.237$ \\
\hline \multirow[t]{2}{*}{ 9905_03 } & $\mathrm{Cu}$ & $\mathrm{Al} 52 \mathrm{~S}$ & 1001.5 & $110.95 \pm 0.481$ & $9.026 \pm 0.048$ & $2.606 \pm 0.022$ & $62.04 \pm 0.580$ \\
\hline & & PI & 507.2 & $72.48 \pm 0.601$ & $6.998 \pm 0.071$ & $3.451 \pm 0.043$ & $36.22 \pm 0.584$ \\
\hline \multirow[t]{2}{*}{ 9905_04 } & $\mathrm{Cu}$ & $\mathrm{Al} 52 \mathrm{~S}$ & 1000.2 & $113.21 \pm 0.090$ & $8.835 \pm 0.027$ & $2.475 \pm 0.022$ & $57.67 \pm 0.553$ \\
\hline & & PI & 493.4 & $75.29 \pm 0.682$ & $6.556 \pm 0.071$ & $3.321 \pm 0.024$ & $32.66 \pm 0.430$ \\
\hline \multirow[t]{2}{*}{ 9905_05 } & $\mathrm{Cu}$ & $\mathrm{Al} 52 \mathrm{~S}$ & 1000.4 & $115.18 \pm 0.235$ & $5.335 \pm 0.091$ & $2.372 \pm 0.022$ & $54.34 \pm 0.533$ \\
\hline & & PI & 506.2 & $77.21 \pm 0.320$ & $4.834 \pm 0.035$ & $1.694 \pm 0.015$ & $12.28 \pm 0.138$ \\
\hline \multirow{2}{*}{ 9905_08 } & $\mathrm{Cu}$ & $\mathrm{Cu}$ & 1972.8 & $351.05 \pm 0.477$ & $5.808 \pm 0.012$ & $1.257 \pm 0.008$ & $65.17 \pm 0.420$ \\
\hline & & PI & 504.8 & $85.79 \pm 1.176$ & $5.898 \pm 0.088$ & $2.067 \pm 0.013$ & $18.29 \pm 0.295$ \\
\hline
\end{tabular}

drocarbons, such as polyethylene and polystyrene, this type of Hugoniot change is indicated in this pressure range. ${ }^{26}$ As our PI contains nitrogen, oxygen, and fluorine, the EOS in the dissociation region may be more complicated. However, laser-driven data first imply the dissociation effect in the PI.

The change of PI Hugoniot should be considered in the design of experiments utilizing the PI. For example, in multilayered flyer experiments ${ }^{13}$ that demonstrated the acceleration of high- $Z$ foil flyer to a speed exceeding $20 \mathrm{~km} / \mathrm{s}$, the acceleration process depends on the first ablation-pressure point on the Hugoniot of PI and its reflected state; the state in the flyer material moves along the reflected-shock curve and the isentrope of PI in the $P-u_{p}$ plane. ${ }^{13}$ The acceleration and compressibility of the PI shell is affected by the EOS in IFE studies.

\section{CONCLUSIONS}

In conclusion, we have presented the equation-of-state measurements for polyimide and have described $\mathrm{KrF}$ laserdriven impedance-matching experiments. The Hugoniot data of PI were obtained up to $65 \mathrm{GPa}$ with the $\mathrm{KrF}$ laser and conventional explosive drivers. A line-imaging ORVIS was used as diagnostics in the laser experiments. The laser experimental results were in good agreement with the reliable explosive results. The change of PI Hugoniot curve was clearly indicated in the relationship between $U_{S}$ and $u_{p}$. In the data below $30 \mathrm{GPa}$, linear-fit parameters $c_{0}$ and $s$ were determined to be 2.15 and 1.65 , respectively. The data above this pressure seem to shift to a new linear relation. The laserdriven results were consistent with the change of Hugoniot curve. This is the first indication of a bent point in the PI Hugoniot with laser-driven shock wave. The bend could originate from the thermal dissociation of the covalent bonds
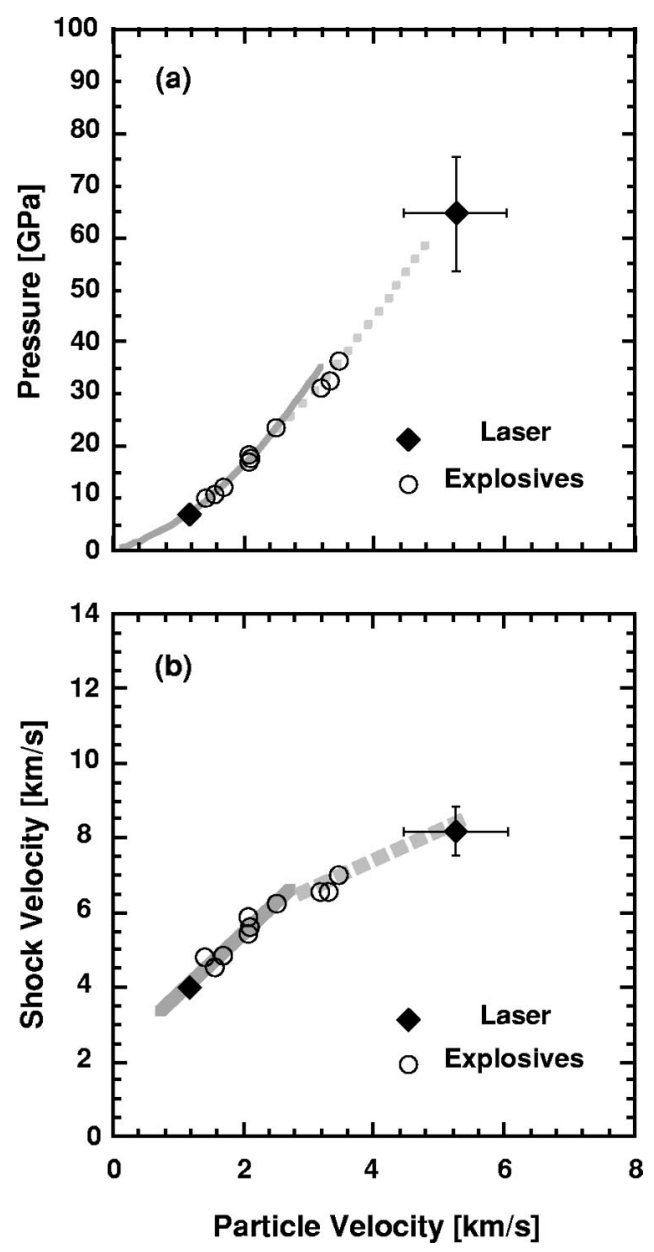

FIG. 3. Summarized PI Hugoniot data. Solid diamonds and open circles are results of the laser and the explosive experiments, respectively. (a) $P-u_{p}$ graph. Solid and dotted curves are fits derived from linear relations in (b). (b) $U_{S}-u_{p}$ graph. The solid curve is a linear-fit to the data below $30 \mathrm{GPa}$ pressure, and dotted curve is a fit to the data above the pressure. 
in the polymeric material. The change of PI Hugoniot should be considered in the design and analysis of experiments utilizing the PI.

\section{ACKNOWLEDGMENT}

This work has been supported by Core Research for Evolutional Science and Technology (CREST) program of Japan Science and Technology Corporation (JST).

${ }^{1}$ W. J. Nellis, M. Ross, and N. C. Holmes, Science 269, 1249 (1995); D. Saumon, G. Chabrier, and H. M. Van Horn, Astrophys. J. 99, 713 (1995); W. J. Nellis, Planet. Space Sci. 48, 671 (2000).

${ }^{2}$ C. S. Yoo, N. C. Holmes, M. Ross, D. J. Webb, and C. Pike, Phys. Rev. Lett. 70, 3931 (1993).

${ }^{3}$ S. W. Haan, S. M. Pollaine, J. D. Lindl, L. J. Suter, R. L. Berger, L. V. Powers, W. E. Alley, P. A. Amendt, J. A. Futerman, W. K. Levedahl, M. D. Rosen, D. P. Rowley, R. A. Sacks, A. I. Shestakov, G. L. Strobel, M. Tabak, S. V. Wever, G. B. Zimmerman, W. J. Krauser, D. C. Wilson, S. V. Coggeshall, D. B. Harris, N. M. Hoffman, and B. H. Wilde, Phys. Plasmas 2, 2480 (1995); J. D. Lindl, ibid. 2, 3933 (1995).

${ }^{4}$ T. R. Dittrich, S. W. Hann, M. M. Marinak, S. M. Pollaine, D. E. Hinkel, D. H. Munro, C. P. Verdon, G. L. Strobel, R. McEachern, R. C. Cook, C. C. Roberts, D. W. Wilson, P. A. Bradley, L. R. Foreman, and W. S. Varnum, Phys. Plasmas 6, 2164 (1999).

${ }^{5}$ R. M. More, K. H. Warren, D. A. Young, and G. B. Zimmerman, Phys. Fluids 31, 3059 (1988).

${ }^{6}$ SESAME, the LANL equation of state database, Los Alamos National Laboratory, LA-UR-92-3407 (1992). Copies may be ordered from the National Technical Information Service, Springfield, Virginia 22161.

${ }^{7}$ R. J. Taylor, J. P. Dahlburg, A. Iwase, J. H. Gardner, D. E. Fyfe, and O. Willi, Phys. Rev. Lett. 76, 1643 (1996); H. Azechi, M. Nakai, K. Shigemori, N. Miyanaga, H. Shiraga, H. Nishimura, M. Honda, R. Ishizaki, J. G. Wouchuk, H. Takabe, K. Nishihara, and K. Mima, Phys. Plasmas 4, 4079 (1997); E. Wolfrum, J. Wark, J. Zhang, D. Kalantar, M. H. Key, B. A. Remington, S. V. Weber, D. Neely, S. Rose, J. Warwick, A. MacPhee, C. L. S. Lewis, A. Demir, J. Lin, R. Smith, and G. J. Tallent, ibid. 5, 227 (1998)

${ }^{8}$ T. A. Hall, S. Ellwi, D. Batani, A. Bernardinello, V. Masella, M. Koenig, A. Benuzzi, J. Krishnan, F. Pisani, A. Djaoui, P. Norreys, D. Neely, S. Rose, M. H. Key, and P. Fews, Phys. Rev. Lett. 81, 1003 (1998); K. A. Tanaka, R. Kodama, H. Fujita, M. Heya, N. Izumi, Y. Kato, Y. Kitagawa, K. Mima, N. Miyanaga, A. Pukhov, A. Sunahara, K. Takahashi, M. Allen, H. Habara, T. Iwatani, T. Matsusita, T. Miyakosi, M. Mori, H. Setoguchi, T. Sonomoto, M. Tanpo, Y. Tohyama, H. Azuma, T. Kawasaki, T. Komeno, O. Maegawa, S. Matsuo, T. Shozaki, Ka. Suzuki, H. Yoshida, T. Yamanaka, Y. Sentoku, F. Weber, T. W. Barbee, Jr., and L. DaSilva, Phys. Plasmas 7, 2014 (2000).

${ }^{9}$ J. J. Sanchez and S. A. Letts, Fusion Technol. 31, 491 (1997).

${ }^{10}$ F.-Y. Tsai, E. L. Alfonso, D. R. Harding, and S. H. Chen, J. Phys. D 34, 3011 (2001).
${ }^{11}$ K. Nagai, T. Takaki, T. Norimatsu, and T. Yamanaka, Macromol. Rapid Commun. 22, 1344 (2001).

${ }^{12}$ The PI is a soluble and high transparent polyimide which is synthesized by the reaction of $2,2^{\prime}$-bis(trifluoromethyl)-4,4' -diaminobiphenyl (TFDB) with $2,2^{\prime}$-bis $\left(3,4^{\prime}\right.$-dicarboxyphenyl)hexafluoropropane dianhydride (6FDA).

${ }^{13}$ K. A. Tanaka, M. Hara, N. Ozaki, Y. Sasatani, S. I. Anisimov, K. Kondo, M. Nakano, K. Nishihara, H. Takenaka, M. Yoshida, and K. Mima, Phys. Plasmas 7, 676 (2000); N. Ozaki, Y. Sasatani, K. Kishida, M. Nakano, N. Miyanaga, K. Nagai, K. Nishihara, T. Norimatsu, K. A. Tanaka, Y. Fujimoto, K. Wakabayashi, S. Hattori, T. Tange, K. Kondo, M. Yoshida, N. Kozu, M. Ishiguchi, and H. Takenaka, J. Appl. Phys. 89, 2571 (2001).

${ }^{14}$ T. Kadono, M. Yoshida, E. Takahashi, I. Matsushima, Y. Owadano, N. Ozaki, K. Fujita, M. Nakano, K. A. Tanaka, H. Takenaka, and K. Kondo, J. Appl. Phys. 88, 2943 (2000).

${ }^{15}$ T. Kadono, M. Yoshida, N. K. Mitani, T. Matsumura, E. Takahashi, I. Matsushima, Y. Owadano, Y. Sasatani, K. Fujita, N. Ozaki, K. Takamatsu, M. Nakano, K. A. Tanaka, H. Takenaka, H. Ito, and K. Kondo, Laser Part. Beams 19, 623 (2001).

${ }^{16}$ Y. B. Zel'dovich and Y. P. Raizer, Physics of Shock Waves and HighTemperature Hydrodynamic Phenomena (Academic, New York, 1966).

${ }^{17}$ See, for example, High-Velocity Impact Phenomena, edited by R. Kinslow (Academic, New York, 1970).

${ }^{18}$ M. Koenig, B. Faral, J. M. Boudenne, D. Batani, A. Benuzzi, S. Bossi, C. Remond, J. P. Perrine, M. Temporal, and S. Atzeni, Phys. Rev. Lett. 74, 2260 (1995); A. M. Evans, N. J. Freeman, P. Graham, C. J. Horsfield, S. D. Rothman, B. R. Thomas, and A. J. Tyrrell, Laser Part. Beams 14, 113 (1996); A. Benuzzi, Th. Löwer, M. Koenig, B. Faral, D. Batani, D. Beretta, C. Danson, and D. Pepler, Phys. Rev. E 54, 2162 (1996); M. Koenig, A. Benuzzi, B. Faral, J. Krishnan, J. M. Boudenne, T. Jalinaud, C. Remond, A. Decoster, D. Batani, D. Beretta, and T. A. Hall, Appl. Phys. Lett. 72, 1033 (1998); M. Koenig, B. Faral, J. M. Boudenne, D. Batani, A. Benuzzi, and S. Bossi, Phys. Rev. E 50, R3314 (1994); R. Cauble, T. S. Perry, D. R. Bach, K. S. Budil, B. A. Hammel, G. W. Collins, D. M. Gold, J. Dunn, P. Celliers, L. B. Da Silva, M. E. Foord, R. J. Wallace, R. E. Stewart, and N. C. Woolsey, Phys. Rev. Lett. 80, 1248 (1998).

${ }^{19}$ S. D. Rothman, A. M. Evans, C. J. Horsfield, P. Graham, and B. R. Thomas, Phys. Plasmas 9, 1721 (2002).

${ }^{20}$ Y. Owadano, I. Okuda, Y. Matsumoto, I. Matsushima, K. Koyama, T. Tomie, and M. Yano, Laser Part. Beams 11, 347 (1993).

${ }^{21}$ The present name is the National Institute of Advanced Industrial Science and Technology (AIST).

${ }^{22}$ T. Kadono, M. Yoshida, N. Kozu, and K. Kondo, Rev. Sci. Instrum. 71, 4674 (2000).

${ }^{23}$ L. M. Barker and Hollenbach, J. Appl. Phys. 43, 4669 (1972).

${ }^{24}$ A. C. Mitchell and W. J. Nellis, J. Appl. Phys. 52, 3363 (1981).

${ }^{25}$ Assuming that the $c_{0}$ and the $s$ of standard material are constant, the inaccuracy of particle velocity, $\left(d u_{p} / u_{p}\right)$ is given by $U_{S} /\left(U_{S}-c_{0}\right)$ $\times\left(d U_{S} / U_{S}\right)$, where $c_{0}$ and $s$ are $y$ intersection and slope in linear relationship between $U_{S}$ and $u_{p}$. When the shock velocity is close to the $c_{0}$, the differential coefficient, $U_{S} /\left(U_{S}-c_{0}\right)$ becomes large.

${ }^{26}$ F. H. Ree, J. Chem. Phys. 70, 974 (1979). 